\title{
Correlation Between Hemodynamic Status and Survival Rates in Severe Burn Patients During Emergency Phase
}

\author{
Rasi Rahagia*, Anggun Pranessia Anggrasari \\ Nurse Profession Department, STIKes Surabaya, Indonesia \\ *rasi.rahagia@stikessurabaya.ac.id
}

\begin{abstract}
Disturbance in the hemodynamic status in severe burn is a serious problem which occurs most frequently in the emergency phase. The hemodynamic status of burn patients is influenced by the physiological response of the body to the characteristics of the burn severity. Therefore, factors influencing the hemodynamic status in the emergency phase is essential to be studied. This study aimed to analyze the relationship between the hemodynamic status and the survival rate of severe burn patients in the emergency phase at RSSA Malang. This research was a documentary analysis employing a retrospective design on 80 samples of the medical records in Combus room of RSSA Malang in the last 2 years. The results of the relationship analysis showed that the factors associated with the survival rate were the systolic blood pressure $(p=0.000)$ and respiratory rate $(p=0.000)$. Thus, monitoring the hemodynamic status in the emergency phase is vital to evaluate the effectiveness of therapy in increasing the survival rate in severe burn patients.
\end{abstract}

Keywords: Survival Rate, Hemodynamic Status, Severe Burn 


\section{STRADA Jurnal Ilmiah Kesehatan}

DOI: $10.30994 /$ sjik.v9i2.475

ISSN: 2252-3847 (print); 2614-350X (online)

Vol.9 No.2 November 2020 Page.1390-1395

\section{BACKGROUND}

The emergency phase in the case of burns is a very determining and deserves special attention from medical personnel, especially nurses. During this phase, severe burns will cause different physiological systemic responses and the emergence of varied local inflammatory mediators in the body (Keck, et al., 2009). The skin plays an essential role as a system to regulate the fluid and electrolyte balance in the body. If there is a disturbance or damage to the skin, a significant amount of fluid and electrolyte will lose causing a decrease in the cardiac output and disturbances in the hemodynamic status in severe burn patients (Dunne \& Rawlins, 2014). This hemodynamic disturbance can create several complications in the human body, such as cardiogenic, hypovolemic, and distributive shock (Snell, et al., 2013). This is the reason of the need of special attention to the severe burn patients in the emergency phase. Prediction in the outcome of treatment therapy and a description of the survival rate of burn patients are one of the most frequently asked questions given by the patient's family, therefore a quantitative measurement of the patient diseases employing a probability index or scoring is essentially needed in deciding the therapeutic policies in the healing process. Moreover, medical personnel need to evaluate new therapies and improve the treatment quality for burn patients, at the same time estimating costs during the treatment (Emara, 2015). According to the study performed by Greaves, Porter, Hodgetts, and Wollard (2006), several factors affect on the survival prognosis of a burn outcome, called burn characteristic factors which include the age, etiology, wound depth level, wound area as compared to the total body surface area, wound location and presence of inhalation injury. All of these burn characteristic factors can affect the hemodynamic status of the burn patient. Therefore, the hemodynamic factors during the emergency phase require a thorough investigation. Several previous studies have been conducted to determine the prognosis of the survival rate of burns associated with several factors. However, there are still no specific studies examining the hemodynamic status as a factor to predict the survival rate of severe burn patients during the emergency phase among adult population.

\section{METHOD}

This research employed a documentary analysis using a retrospective cohort study design on 80 medical record samples in the Combus room of RSSA Malang from the period of May 2018-May 2020. This research passed the ethical clearance of the Faculty of Medicine, Brawijaya University in 30 June 2020 with number 123 / EC / KEPK / 06/2020. Data in this study were collected using purposive sampling technique with the inclusion criteria of severe burns patients with a wound area of more than $20 \%$ of the total body surface area caused by thermal injury. The instrument used was a data collection sheet recording the hemodynamic status which included the systolic blood pressure, heart rate and respiratory rate measured 8 hours after the administration of fluid resuscitation as the independent variables and the survival rate as the dependent variable. The data were analyzed by using the Spearman correlation test with a confidence level of $95 \%$.

\section{RESULTS}

The survival rate of severe burn patients in the emergency phase in Combus room of RSSA Malang reached $87,20 \%$ or 68 patients from a total 80 samples according to the medical records. 


\section{STRADA Jurnal Ilmiah Kesehatan}

DOI: $10.30994 /$ sjik.v9i2.475

ISSN: 2252-3847 (print); 2614-350X (online)

Vol.9 No.2 November 2020 Page.1390-1395

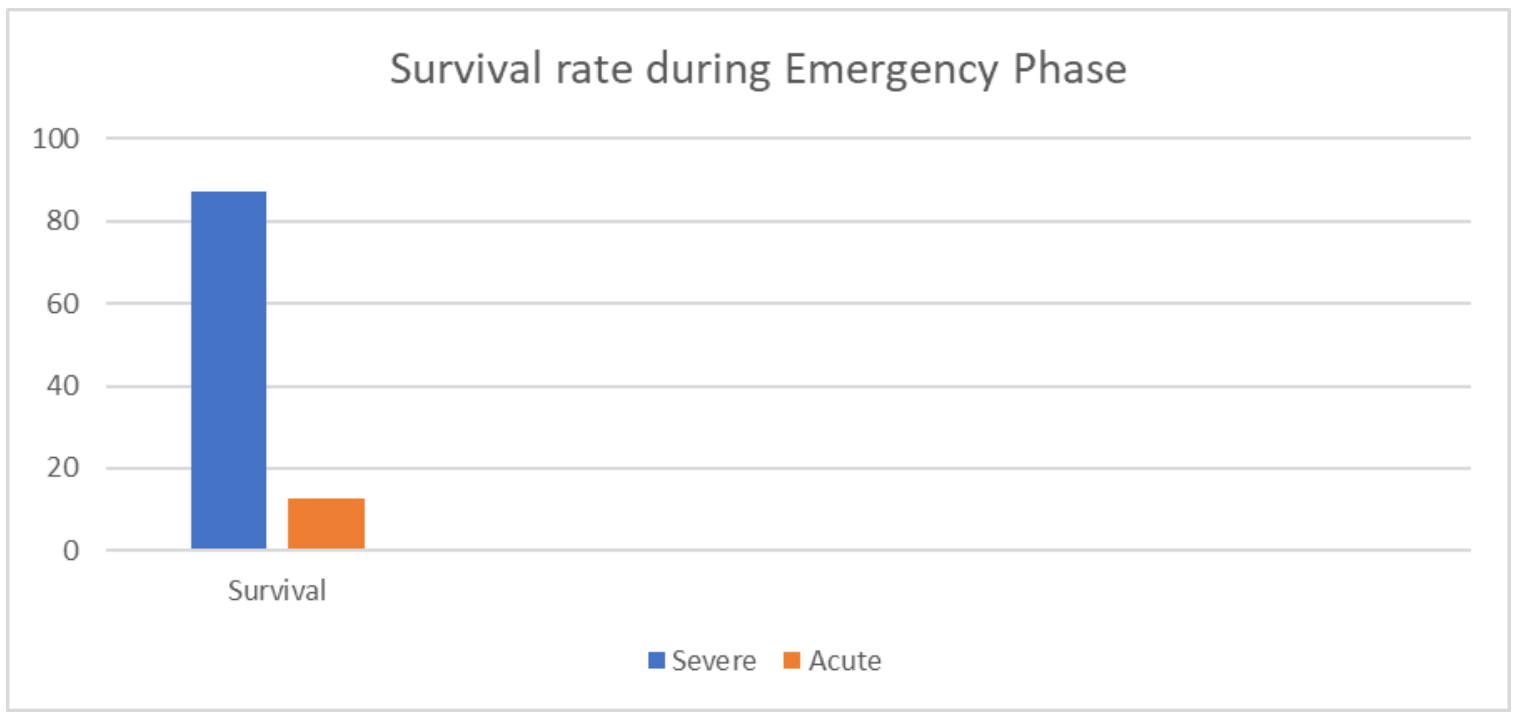

Figure 1. Description of Surviving Burn Patients

Table 1. Hemodynamic Status ( Systolic Blood Pressure, Heart Rate and Respiratory Rate).

\begin{tabular}{lcc}
\hline \multicolumn{1}{c}{ Variable } & Median & Min-Max \\
\hline Systolic Blood Pressure (SBP) & 110 & $80-160$ \\
Heart Rate (HR) & 89 & $46-110$ \\
Respiratory Rate (RR) & 20 & $18-30$ \\
\hline
\end{tabular}

According to Table 1, the median values were $110 \mathrm{mmHg}$ of systolic blood pressure, $89 /$ minute of heart rate and 120/minute of respiratory rate.

Table 2. Correlation Analysis Test of Hemodynamic Status and Survival Rate

\begin{tabular}{lcc}
\hline \multirow{2}{*}{ Hemodynamic Status } & \multicolumn{2}{c}{ Survival rate } \\
\cline { 2 - 3 } & $\mathbf{P}$ & $\mathbf{r}$ \\
\hline SBP & 0.000 & 0.481 \\
HR & 0.217 & -0.145 \\
RR & 0.000 & -0.518 \\
\hline
\end{tabular}

Based on Table 2, the hemodynamic status affecting on the survival rate of severe burn patients during the emergency phase in Combus room of RSSA Malang included the systolic blood pressure and the respiratory rate, with a $p$ value of 0.000 , in which $p<\alpha$ (0.05).

\section{DISCUSSION}

This study found that the survival rate of severe burn patients during the emergency phase retrospectively from May 2018 to May 2020 reached $87.20 \%$, which means that the survival rate of severe burn patients during the emergency phase in the Combus room of RSSA Malang is significantly high. Meanwhile, a study conducted by Chen et al. (2012) reported that the mortality of burn patients during the acute phase up to the first 72 hours 


\section{STRADA Jurnal Ilmiah Kesehatan}

DOI: $10.30994 /$ sjik.v9i2.475

ISSN: 2252-3847 (print); 2614-350X (online)

Vol.9 No.2 November 2020 Page.1390-1395

showed a smaller result of $2.08 \%$. The difference in mortality rates can be due to the number of samples used. Chen et al. (2012) used a fairly large sample of 25,687 medical records with 482 of which were medical records of patients who died within the first 72 hours, while this study used 80 medical records with 12 of which were the medical records of patients who died within the first 48 hours. In contrast, the study reported by Davis et al., (2012) showed that the survival rate of burn patients in the emergency phase was lower than this study, by 54\%. The difference in the survival rate is due to the different characteristics of the samples used in terms of age groups, in which in this study specifically used a sample of adult patients while Davis et al., (2012) used samples from elderly patients. This indicates that the younger the patients the higher the survival rates. This is also supported by a study conducted by Zanasi et al., (2015). Their study reported that the elderly group had a smaller survival rate with a higher risk of death. The high mortality statistics in the elderly with burns is the result of a combination of various functional disorders in the body (Rahayuningsih, 2012).

The hemodynamic status of severe burn patients 8 hours after the first fluid resuscitation can be seen in Table 1. The patient's hemodynamic status is represented by stable systolic blood pressure, heart rate, and respiratory rate 8 hours after the fluid resuscitation. Based on Table 1, the average respondent's systolic blood pressure was $110.72 \mathrm{mmHg}$, the average heart rate of respondents was 89.16 times per minute and the average respiratory rate of respondents was 20.03 times per minute. This indicates that the average respondent in this study has a normal systolic blood pressure and heart rate after 8 hours of fluid resuscitation, and a slightly-exceeding-normal respiratory rate value. In severe burns, a large amount of fluid loses causing hemodynamic disturbances during the emergency phase (Dunne \& Rawlins, 2014). The hemodynamic status disturbances can cause several complications such as cardiogenic, hypovolemic, and distributive shocks which are characterized by hypotension, tachycardia or bradycardia, and poor perfusion (Snell et al., 2013). However, the hemodynamic status investigated in this study were the systolic blood pressure, heart rate, and respiratory rate measured 8 hours after the fluid resuscitation, which means that there has been a system of hemodynamic status correction by administering the fluid resuscitation within the first 8 hours.

According to Smeltzer and Bare (2008), systolic blood pressure indicates the pressure in the arteries when the heart contracts (heart rate) or the maximum pressure in the arteries at any one time. Systolic blood pressure (SBP) is expressed by a higher number when read on a blood pressure measuring device with a normal value of $90-120 \mathrm{mmHg}$. Therefore, SBP levels of the severe burn patients in this study are considered to be in the normal range. In addition, the blood pressure is influenced by the cardiac output and peripheral resistance, in which the cardiac output is the amount of blood pumped by the ventricles at a duration of time which is shown by the multiplication of the stroke volume and the heart rate (Sherwood, 2012). Heart rate is the frequency of the heartbeat for 1 minute indicating the work of the heart in pumping blood with normal values between 60 and 100 times per minute (Stewart, 2003). Therefore, the heart rate of the severe burn patients in this study can be considered normal. However, the respiratory rate of the severe burn patients in this study shows a value that slightly exceeds the normal range. Yuan, Drost, and Mclvor (2013) reported that the normal range of respiratory rate in adults is between 12 and 20 times per minute. Thus, it can be concluded that the average respondent in this study has a fairly stable hemodynamic status 8 hours after the fluid resuscitation.

The hemodynamic status shows a positive relationship with the survival rate of severe burn patients based on Table 2 . The hemodynamic status that has a significant 


\section{STRADA Jurnal Ilmiah Kesehatan}

DOI: $10.30994 /$ sjik.v9i2.475

ISSN: 2252-3847 (print); 2614-350X (online)

Vol.9 No.2 November 2020 Page.1390-1395

correlation with the survival rate of patients in the first 48 hours include the systolic blood pressure and respiratory rate measured 8 hours after the fluid resuscitation with a moderate correlation in both, while the heart rate is not significantly correlated with the survival rate. These results are consistent with Davis et al., (2012). Their study found that the respiratory rate and blood pressure greatly affect the survival rate of severe burn patients. The relationship between the respiratory rate and survival rate shows a negative direction, which means that the greater the patient's respiratory rate, the less the patient's survival rate is. The results of the uni-variance test in this study show that the average systolic blood pressure of the respondents in this study was 110.72, which means it is still in the normal range. According to Gokdemir et al. (2012), the systolic blood pressure that can be a risk of mortality for burn patients is a systolic blood pressure of less than $90 \mathrm{mmHg}$ as a sign of hypotension. In this study, the heart rate is not significantly correlated with survival rate. This is possibly due to other factors such as the body's physiological response to the fluid resuscitation. This also is explained through a study by Baxter and Shires (1998) cited in Alvarado et al. (2009). They found that the cardiac output decreases during the first 4 hours after burns which involve $30 \%$ of the burn surface area and showed an optimal cardiac output response in the experimental animals during the first 8 hours after the fluid resuscitation. Moreover, the average heart rate of the severe burn patients in this study is still in the normal range, which is 89.16 times per minute.

\section{CONCLUSION}

Based on the above discussion, it can be concluded that the hemodynamic status that is significantly related to the survival rate of burn patients are systolic blood pressure and respiratory rate and both have a significant relationship. Therefore, hemodynamic monitoring during the emergency phase is very essential to evaluate the effectiveness of therapy to increase the survival rate of the severe burn patients.

\section{REFERENCE}

Alvarado, R. Chung, K. K., Cancio, L. C., Wolf, S. E. (2009). Burn resuscitation : Review. Burns 35, 4-14.

Dunne, J. A. \& Rawlins, J. M. (2014). Management of burns. Surgery, 32 (9).

Emara, S. (2015). Prognostic Indicators in Acute Burned Patients-A Review. Journal of Acute Disease, 85-90.

Gokdemir, M. T., et al. (2012). Clinical Outcome of Patients With Severe Burns Presenting to the Emergency Department. J Curr Surg 2(1), 17-23.

Greaves, Porter, Hodgetts, \& Wollard. (2006). Emergency Care: A Textbook for Paramedics, second edition. Italy: Saunder Elsevier.

Davis, J. S., Prescott, A. T., et al. (2012). A new algorithm to allow early prediction of mortality in elderly burn patients. Burn, 38: 1114-1118.

Chen, C., Chen, L., Wen, B., Liu, S., \& Ma, H. (2012). Objective estimates of the probability of death in acute burn injury: A proposed Taiwan burn score. Trauma Acute Care Surg, 73:1583-1589.

Clancy, J. \& McVivar, A. (2009). Physiology and Anatomy for Nurses and Healthcare Practitioners: a Homeostatic Approach $3^{\text {rd }}$ edition. US: CRC Press.

Karpelowsky, J.S. \& Rode, H. (2014). Basic principles in the management of thermal injuries. South African Family Practice, 50(3), 24-31.

Keck, M. Herndon, D.H., Kamolz, L.P., Frey, M., \& Jeschke, M.G. (2009). Pathofisiology of Burn. Wien Med Wochenschr, 159 (13), 327-336. 


\section{STRADA Jurnal Ilmiah Kesehatan}

DOI: $10.30994 /$ sjik.v9i2.475

ISSN: 2252-3847 (print); 2614-350X (online)

Vol.9 No.2 November 2020 Page.1390-1395

Rahayuningsih, T. (2012). Penatalaksanaan Luka Bakar (Combustio). Profesi, 8.

Sherwood, L. (2012). Fisiologi Manusia dari Sel ke Sistem Edisi 6. Jakarta: EGC.

Smeltzer \& Bare. (2008). Textbook of Medical Surgical Nursing Vol.2. Philadelphia: Linppincott William \& Wilkins.

Snell, J. A., Loh, W. N., TMahambrey, T., \& Shokrollahi K. (2013). Clinical review: The critical care management of the burn patient. Critical Care, 17 (241).

Stewart, J. V. (2003). Vital Sign and Resuscitation. USA: Landes Bioscience.Yuan, G., Drost, N. A., \& McIvor, R.A. (2013). Respiratory rate and breathing pattern. MUMJ, $10(1)$.

Zanasi, S., de Abreu, L. C., Heinke, T., et al. (2015). Factors associated with survival of burned patients. International Archives of Medicine, 8 (77), doi: 10.3823/1676. 